\title{
The relationship between MTHFR C677T gene polymorphism and essential hypertension in a sample of an Algerian population of the Oran city
}

\section{Type of article: Conference abstract}

Asma Amrani-Midoun1*, Soto Romuald Kiando2,3 ,Cyrielle Treard2,3 , Xavier Jeunemaitre2,3,4 Nabila Bouatia-Naji 2,3

1* Biotechnology Department, Faculty of Sciences of Nature and Life, University of Oran 1 Ahmed Benbella, Oran, Algeria

2INSERM, UMR970 Paris Cardiovascular Research Center (PARCC), Paris F-75015, FRANCE

3Paris-Descartes University, Sorbonne Paris Cité, Paris 75006, FRANCE

4AP-HP, Department of Genetics, HôpitalEuropéen Georges Pompidou, Paris, F-75015, FRANCE

Dr.asma.amrani@gmail.com

\begin{abstract}
:
Background

Many studies have investigated the role of 5,10-methylenetetrahydrofolate reductase (MTHFR) C677T gene polymorphism in essential hypertension (EH), but with conflicting results.

Aim

To determine the eventual association between 5,10-methylenetetrahydrofolate reductase (MTHFR) C677T gene polymorphism and hypertension in a sample of Algerian population from the Oran city. Methods

A case-control study has been performed in 154 subjects including 82 hypertensives defined as subjects with elevated systolic blood pressure $\mathrm{SBD} \geq 140 \mathrm{mmHg}$ and or sustained diastolic blood pressure DBP $\geq 90 \mathrm{mmHg}$, and 72 normotensive subjects. Polymerase chain reaction (PCR) combined with restrictive fragment length polymorphism (RFLP) was used to detect the MTHFR C677T variant.

Results

We observe no significant differences between allelic and genotypic frequencies between cases and controls for $\mathrm{C} 677 \mathrm{~T}$ polymorphism $(\mathrm{OR}=1.51,95 \% \mathrm{CI}=0.89-2.56, \mathrm{P}=0.13)$. Analyses adjusted for age, sex and body mass index improved the association level, though the association was still not significant $(30 \%$ vs. $22 \%, \mathrm{OR}=1.75,95 \% \mathrm{CI}=0.95-3.24, \mathrm{P}=0.07)$.

Conclusion

This work showed that genetic polymorphism related to the MTHFR gene (C677T) is not associated with the risk of hypertension in this sample of Algerian population. Larger case- control samples are required to clearly assess the role of this genetic variant in $\mathrm{EH}$.

Keywords: MTHFR C677T gene polymorphism; hypertension; Algerian population; case-control study.
\end{abstract}

\section{Conflict of interest statement}

This article is an abstract selected from the International Congress on Health Sciences and Medical Technologies, Algiers, Algeria, October 21-23, 2018.

\section{Authors' biography}

No biography

\section{References}

No references 